\title{
Simulating yield response of rice to salinity stress with AquaCrop model
}

M. Shahjahan Mondal ${ }^{1}$, Abul Fazal M. Saleh ${ }^{1}$, Md. Abdur Razzaque Akanda ${ }^{2}$, Sujit K. Biswas ${ }^{2}$, Abu Zofar Md. Moslehuddin ${ }^{3}$, Sinora Zaman ${ }^{1}$, Attila N. Lazar ${ }^{4}$, Derek Clarke ${ }^{4}$

${ }^{1}$ Institute of Water and Flood Management, Bangladesh University of Engineering and Technology, Dhaka-1000, Bangladesh

${ }^{2}$ Irrigation and Water Management Division, Bangladesh Agricultural Research Institute, Gazipur-1701, Bangladesh

${ }^{3}$ Department of Soil Science, Bangladesh Agricultural University, Mymensingh-2202, Bangladesh

${ }^{4}$ University of Southampton, United Kingdom

\begin{abstract}
The FAO AquaCrop model has been widely applied throughout the world to simulate crop responses to deficit water applications. However, its application to saline conditions is not yet reported, though saline soils are common in coastal areas. In this study, we parameterized and tested the model to simulate rice yield under different salinity regimes. An experimental study with BRRI Dhan 28, a popular boro rice variety in Bangladesh, was conducted in the dry season of 2013 at Bangladesh Agricultural Research Institute, Gazipur with five levels of saline water irrigation, three replicates for each level, to collect data and information required in the model. Also, field monitoring was carried out at Satkhira in southwest coastal region to collect data and information based on farmers' practices and to further validate the model. The results indicated that the AquaCrop model with most of its default parameters could capture the variation of rice yield with the variation of salinity reasonably well. The root mean square error and mean absolute error of the model yield were only $0.14 \mathrm{t} / \mathrm{ha}$ and $0.03 \mathrm{t} / \mathrm{ha}$, respectively. The crop response versus soil salinity stress curve was found to be convex in shape with a lower threshold of $2 \mathrm{dS} / \mathrm{m}$, an upper threshold of $10 \mathrm{dS} / \mathrm{m}$ and a shape factor of 2.4. The model would be a useful tool in assessing the potential impacts of future changes in water and soil salinity as well as climatic parameters on rice yield, in the coastal region of Bangladesh .
\end{abstract}

Keywords: AquaCrop model, salinity, rice, Bangladesh

\section{Introduction}

The Food and Agriculture Organization (FAO) released a crop growth and yield simulation model, called AquaCrop (Raes et al., 2009; Steduto et al., 2009a), targeting at extension service providers, consultants, water managers and policy makers. The model is relatively easy to use and the 33 types of required input data related to climate, soil, agricultural techniques and crop characteristics can be readily derived from an experimental research. Since its release in 2009, the model has been parameterized and tested on a number of cereal crops including maize in USA (Heng et al., 2009; Hsiao et al., 2009), Spain (Heng et al., 2009), India (Abedinpour et al., 2012) and Serbia (Stricevic et al., 2011), wheat in Iran (Andarzian et al., 2011; Salemi et al., 2011) and Canada (Mkhabela and Bullock, 2012), sunflower in Serbia (Stricevic et al., 2011), barley in Ethiopia (Araya et al., 2010a), cotton in Syria (Hussein et al., 2011), sugar beet in 
Serbia (Stricevic et al., 2011), teff in Ethiopia (Araya et al., 2010b), and quinoa in Bolivia (Geerts et al., 2010). These studies demonstrated that the model was able to simulate the biomass development and grain yield of these crops with reasonable accuracy.

Though the model has been tested for a number of crops in a number of diverse climatic and agro-ecological settings, its application to rice, which is a staple food providing basic nutrition for more than half of the world's population, has been very limited. The few studies that have been made on rice using AquaCrop (in China by Lin et al., 2012, India by Bhattacharya and Panda, 2013, Tanzania by Katambara et al., 2013, western Africa by Nikolaus, 2013 and southeast Asia by Mainuddin et al., 2013) either did not report many important model parameters or did not properly parameterize the model. Furthermore, no study has so far been made on any crop to test the performance of its salinity module. This study was conducted to evaluate the performance of the AquaCrop model to simulate the yield of dry season rice irrigated with different saline water in Bangladesh.

Rice is the most important staple food crop in Bangladesh, as elsewhere in south and southeast Asia. Rice covers about $77.1 \%$ of the total cropped area of 15.0 million hectares (Mha) and $79.9 \%$ of the total irrigated area of $6.8 \mathrm{Mha}$ in the country (BBS, 2011a, b). The demand for clean rice presently stands at about 28.8 million tons (Mt) (WARPO, 2000). This demand of rice arises from the country's total population of 150 million, which is increasing at a rate of $1.4 \%$ per annum (BBS, 2011c) and as a result the cereal demand is increasing at a rate of $0.3 \mathrm{Mt}$ per annum to feed the ever arching population (GED, 2011). However, the land available for agriculture is decreasing at a rate of $1 \%$ per annum (MoA, 2013).

More than 30\% of the cultivable land in Bangladesh is in the coastal and off-shore areas, of which about $37 \%$ is affected by varying degrees of salinity. Spatial extent of saline area is increasing over time due to reduction in freshwater inflow into the rivers from upstream, introduction of brackish water for shrimp cultivation, increase in high tidal water level, etc. (SRDI, 2012; Mondal et al., 2013). Salt affected area in the country has increased by about 27\% between 1973 and 2009 (SRDI, 2012). Sea level rise, increase in temperature and erratic pattern of rainfall due to climate change are expected to further aggravate the salinity situation. It is thus necessary to assess the effects of soil and water salinity, particularly given the future threats of increased salinity due to sea level rise, on food security, in particular on rice security, of the country. The AquaCrop model with salinity module can be useful in those purposes. It is to be noted that saline or salt affected soils are common in coastal areas in tropical, arid and semi-arid regions.

\section{AquaCrop model}

AquaCrop is a canopy-level and engineering type of crop model, mainly focused on simulating the attainable crop biomass and harvestable yield in response to the water available (Steduto et al., 2009). It has achieved significant improvement in accuracy over Doorenbos and Kassam (1979) while maintaining adequate simplicity and robustness. It avoids the confounding effect of the nonproductive consumptive use of water on yield by separating the evapotranspiration (ET) into crop transpiration ( $\mathrm{T}$ ) and soil evaporation (E). Moreover, in AquaCrop, the functional relationship among different variables is implemented at a daily time scale, which is closer to the 
time scale of crop responses to water deficits (Steduto et al., 2009a). In AquaCrop, soil, crop and atmosphere is considered as a continuum by including the soil, with its water balance; the plant, with its growth, development and yield processes; and the atmosphere with its thermal regime, rainfall, evaporative demand and carbon dioxide $\left(\mathrm{CO}_{2}\right)$ concentration. Additionally, some management aspects, such as irrigation and soil fertility, which affect crop development, water productivity and crop adjustments to stresses, and therefore final yield, are explicit in the model. The details of the model can be found in Steduto et al. (2009a) and Raes et al. (2009).

For each day of the simulation period, AquaCrop requires minimum and maximum air temperatures, reference crop evapotranspiration $\left(\mathrm{ET}_{0}\right)$ and rainfall. Temperature data are used to calculate growing degree day (GDD), which determines crop development and phenology. $\mathrm{ET}_{0}$ is a measure of evaporative demand of the atmosphere. Atmospheric $\mathrm{CO}_{2}$ concentration, which influences canopy expansion and crop water productivity, is also needed. Physical characteristics of the root zone soil, including saturated hydraulic conductivity, field capacity and permanent wilting point, are required in determining root system development and water budgeting.

Canopy expansion and cover, which are determinants of crop transpiration, are simulated from the initial and maximum canopy covers $\left(\mathrm{CC}_{0}\right.$ and $\mathrm{CC}_{\mathrm{x}}$, respectively) using two canopy growth equations. Canopy cover during its declining phase is simulated from the $\mathrm{CC}_{\mathrm{x}}$ and starting time of canopy senescence using an exponential decay equation. A canopy growth coefficient (CGC), which is a conservative parameter, is used in the growth equations and a canopy decline coefficient (CDC), which is also conservative at least to a certain extent, in the decay equation. The green canopy cover is also adjusted for micro-advective effects (CC*) (Raes et al., 2009).

Crop transpiration in AquaCrop is calculated from the adjusted green canopy cover (CC ${ }^{*}$ ) and $\mathrm{ET}_{0}$. The reduction in transpiration due to canopy ageing between the occurrences of maximum canopy cover and canopy senescence is taken into consideration with an ageing coefficient ( $f_{\text {age }}$

). The more marked reduction in transpiration since the occurrence of canopy senescence is further taken into consideration with another coefficient $\left(f_{\text {sen }}\right)$.

The water productivity normalized for $\mathrm{ET}_{0}$ and $\mathrm{CO}_{2}$ concentration (WP ${ }^{*}$ ) and the harvest index $\left(\mathrm{HI}_{0}\right)$ are required to simulate the biomass and yield of a crop.

A deficit in root zone water content slows canopy expansion rate, reduces stomatal conductance and triggers early canopy senescence (Steduto et al., 2009b). These effects are assessed in AquaCrop through three convex shaped water stress-response curves ( $K_{s}$ curves). Water deficit in the root zone may also provoke stomatal closure, which results in a drop in crop transpiration (Raes et al., 2009). Such drop in transpiration is simulated by multiplying the crop transpiration when well watered with a stress coefficient for stomatal closure $\left(K_{S_{s t o}}\right)$. Water stress, depending on its timing and severity and determinancy of a crop, may enhance or reduce harvest index (HI), which is used to obtain crop yield from final biomass. In AquaCrop, HI is adjusted in four ways for the more common stress levels, plus another adjustment for pollination failure (Steduto et al., 2009). The first four adjustments are for inhibition of leaf growth, for inhibition of stomata, for reduction in green canopy duration due to accelerated senescence, and for effect of preanthesis stress related to reduction in biomass. Pollination failure occurs due to severe water stress, cold 
or high temperature and is quantified as a fraction of the total number of flowers that fail to pollinate.

Soil fertility affects WP*, CGC, $\mathrm{CC}_{\mathrm{x}}$ and canopy senescence of a crop. AquaCrop offers a semiquantitative option to assess the effects of the fertility regime on these parameters and hence on the biomass and yield response. The use of field bunds allows retention of water on the soil surface and controls surface runoff and infiltration. Irrigation methods, and the timing and depths of the irrigations are specified in the irrigation file of AquaCrop. The quality of irrigation water and the quality of soil at the beginning of a crop season in terms of water and soil salinity, respectively, are also required as inputs in AquaCrop.

\section{Materials and Methods}

For calibration and validation of the AquaCrop model, a field experiment was conducted with the boro rice of variety BRRI Dhan 28 at the Bangladesh Agricultural Research Institute (BARI) farm in Gazipur (Figure 1). Gazipur is located at about $55 \mathrm{~km}$ north to Dhaka, the capital of Bangladesh, and has an elevation of about $8 \mathrm{~m}$ above mean sea level. The area has a sub-tropical monsoonal climate. Three types of rice (boro, aus and aman) are cultivated in three different seasons in Bangladesh. Boro rice is cultivated with full irrigation during the months of December to May in the dry season and presently covers about 56\% of total rice production (BBS, 2011a). BRRI Dhan 28 is the most popular boro rice variety in Bangladesh. It is an early maturing, short duration, high yielding variety with a life cycle of 140 days from sowing to harvesting and an average yield of 5.0-6.0 t/ha in farmers' fields (BRRI, 2004). It is a salinity sensitive variety with a salt tolerance level of about $4 \mathrm{dS} / \mathrm{m}$.

The rice seedlings of 41 days old were transplanted on 24 January, 2013 and harvested on 5 May. Five levels of irrigation water salinity with three replicates were allocated to fifteen experimental plots laid in a completely randomized design. The size of each plot was $2 \mathrm{~m} \times 3.5 \mathrm{~m}$. The first treatment $\left(T_{1}\right)$ was the irrigation of the rice with a water salinity of $3 \mathrm{dS} / \mathrm{m}$ throughout the growing season. The second, third and fourth treatments $\left(T_{2}, T_{3}\right.$ and $T_{4}$, respectively) were with the irrigation water salinity of 6,9 and $12 \mathrm{dS} / \mathrm{m}$, respectively. The fifth treatment $\left(\mathrm{T}_{5}\right)$ was with the increasing irrigation water salinity from transplanting to near maturity ( $3 \mathrm{dS} / \mathrm{m}$ up to 25 days after transplanting (DAT), $6 \mathrm{dS} / \mathrm{m}$ during 26-50 DAT, $9 \mathrm{dS} / \mathrm{m}$ during 51-75 DAT and 12 $\mathrm{dS} / \mathrm{m}$ during the rest of the growing period).

The salinity in irrigation water was created artificially with a 2:1 mixture of sodium and calcium chlorides. Five overhead reservoirs were installed to provide saline water irrigation to the five types of experimental plots. About $1120 \mathrm{~mm}$ of irrigation was provided with a total of 90 irrigations to each experimental plot. In addition, about $200 \mathrm{~mm}$ of irrigation water was applied during the land preparation. Thus, there was no deficiency of irrigation water to the experimental plots. There were also four rainfall events with a total of $43 \mathrm{~mm}$ during the growing period. 


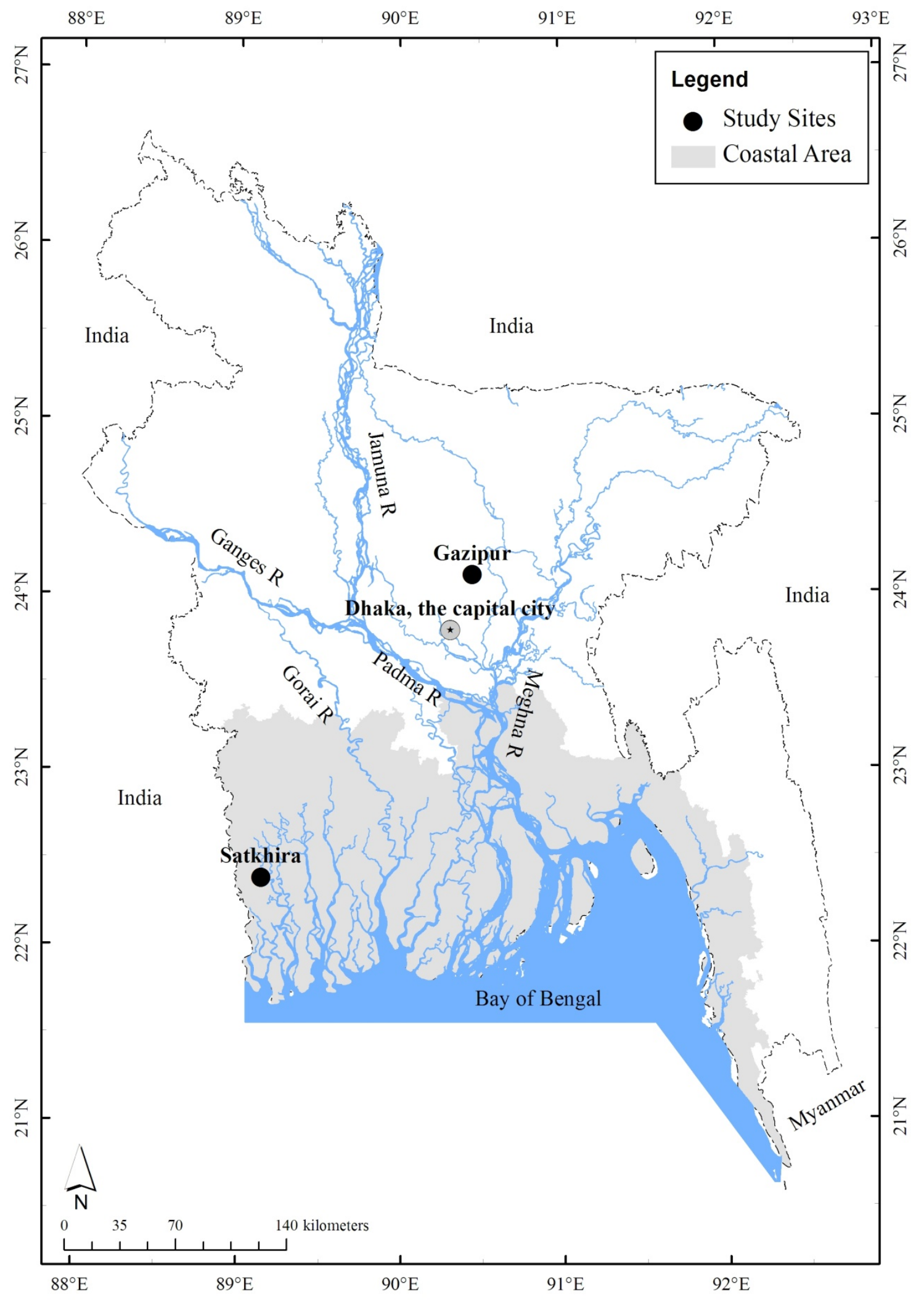

Figure 1: Locations of the experimental and field sites in Bangladesh 
The soil of the BARI farm was analyzed for its texture and fertility. The soil texture was found to be silty loam and the required fertilizer doses were estimated to be 245, 90, 120 and $83 \mathrm{~kg} / \mathrm{ha}$ for urea, triple super phosphate, murate of potash and zypsum, respectively. Urea was applied in three equal splits during the land preparation, $30 \mathrm{DAT}$ and $60 \mathrm{DAT}$. The other fertilizers were applied during the final land preparation. In addition, intercultural operations were done and pesticides were applied when required.

All the physiological and yield contributing characters of rice were recorded for each plot. Canopy cover was estimated from the leaf area index, and above ground biomass was measured from the crop cut at harvest.

In addition to the above experiments, a field monitoring program was carried out in the same season in Satkhira district of southwest coastal region to gather data and information required in AquaCrop as per local farmers' practices. The farmer transplanted the same variety of rice on 8 February 2013 and harvested on 8 May. He provided different fertilizers according to the local practice and the doses, which were adequate for the crop as per fertilizer recommendation for the area (BARC, 2012). A total of 17 irrigations were applied to the field and the soil salinity varied between 3.42 and $8.88 \mathrm{dS} / \mathrm{m}$. There was $78 \mathrm{~mm}$ of rainfall in Satkhira during the growing period of rice.

Daily climatic data, such as maximum and minimum temperature, sunshine hour, relative humidity, wind speed and rainfall, during the crop season were collected from a nearby weather station of Bangladesh Rice Research Institute (BRRI), Gazipur. These data for Satkhira were collected from the local office of the Bangladesh Meteorological Department (BMD). $\mathrm{ET}_{0}$ was calculated for both locations following the FAO Penman-Monteith equation (Allen et al., 1998) with the $\mathrm{ET}_{0}$ calculator. The daily $\mathrm{ET}_{0}$ values for the growing season are given in Figure 2. The $\mathrm{ET}_{0}$ values vary between 1 and $6 \mathrm{~mm} /$ day at Gazipur and between 1 and $7 \mathrm{~mm} /$ day at Satkhira.

\section{Results and Discussion}

The strategy followed in calibration and validation of the AquaCrop model with saline water irrigation was calibrating the model with the second treatment $\left(\mathrm{T}_{2}\right)$ and validating it with the third $\left(T_{3}\right)$, fourth $\left(T_{4}\right)$ and fifth $\left(T_{5}\right)$ treatments while keeping the first treatment $\left(T_{1}\right)$ as the reference treatment in all the four cases. This provided a rigorous testing of the applicability of the selected model parameters in quite diverse salinity regimes. The input parameters, including the phenological observations, used in the model are provided in Table 1. Most of the parameters used in the model are according to the suggested values in the AquaCrop Reference Manual (Raes et al., 2012). The canopy decline coefficient was found to be 0.5\%/GDD and the canopy growth coefficient to be $0.8 \% / G D D$, both of which were at the higher sides of the suggested values. However, slightly smaller values for both the lower and upper salinity thresholds (2 and $10 \mathrm{dS} / \mathrm{m}$, respectively) than that suggested in the AquaCrop Manual ( 3 and $11.3 \mathrm{dS} / \mathrm{m}$ ) provided a better simulation of the observed rice yield. The shape of the salinity stress coefficient curve was found to be convex with a shape factor of 2.4 (Figure 3). The model calibrated grain yield was $5.52 \mathrm{t} / \mathrm{ha}$ as against an average observed grain yield of $5.49 \mathrm{t} / \mathrm{ha}$ in the second treatment. The calibrated biomass was $11.48 \mathrm{t} / \mathrm{ha}$ and the observed biomass was $11.19 \mathrm{t} / \mathrm{ha}$. The model results 
also indicated that the potential biomass yield in absence of salinity stress would be about 13.54 t/ha.
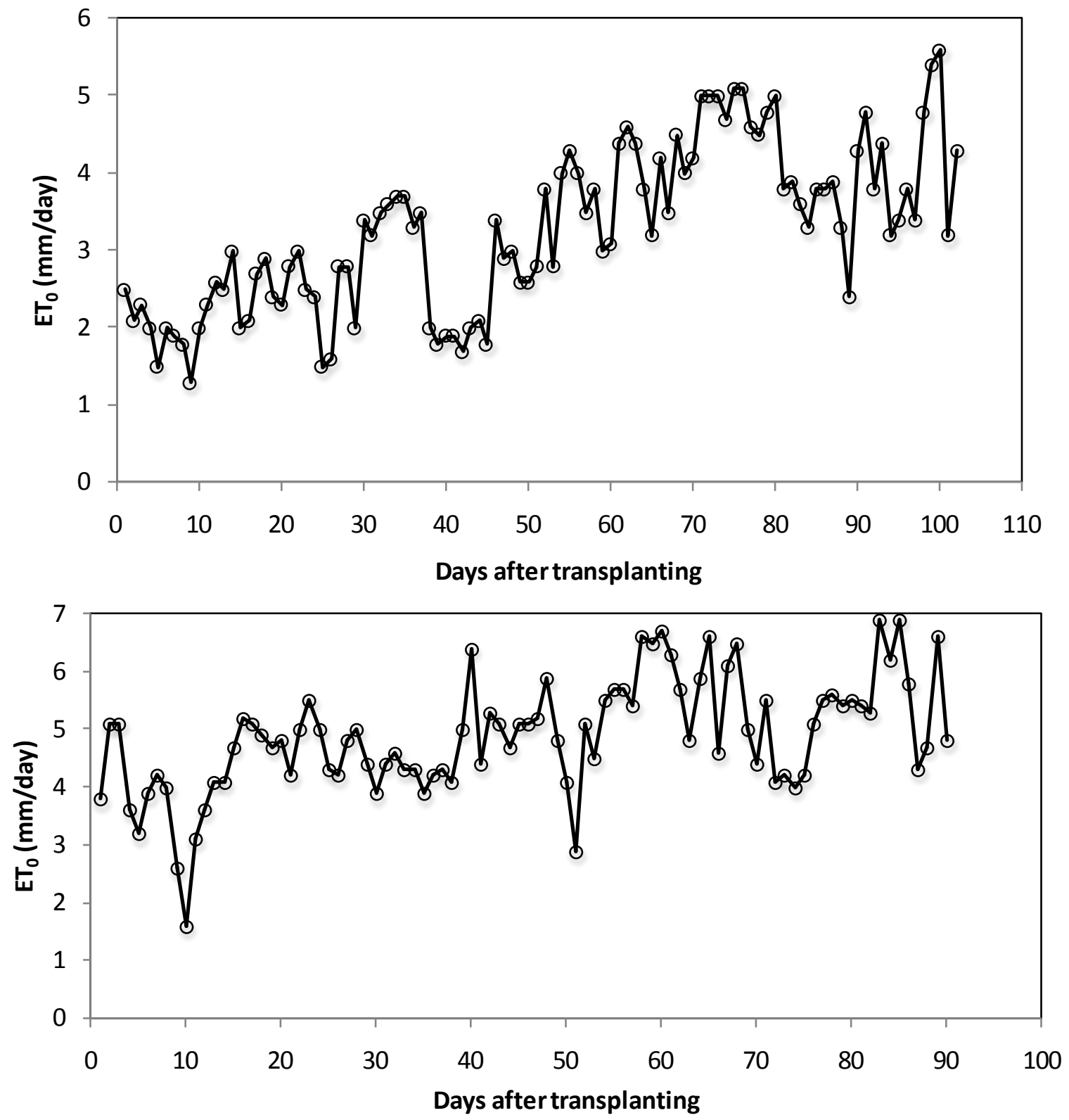

Figure 2: Variation of daily $\mathrm{ET}_{0}$ values at Gazipur (top) and Satkhira (bottom) during the boro rice growing period 


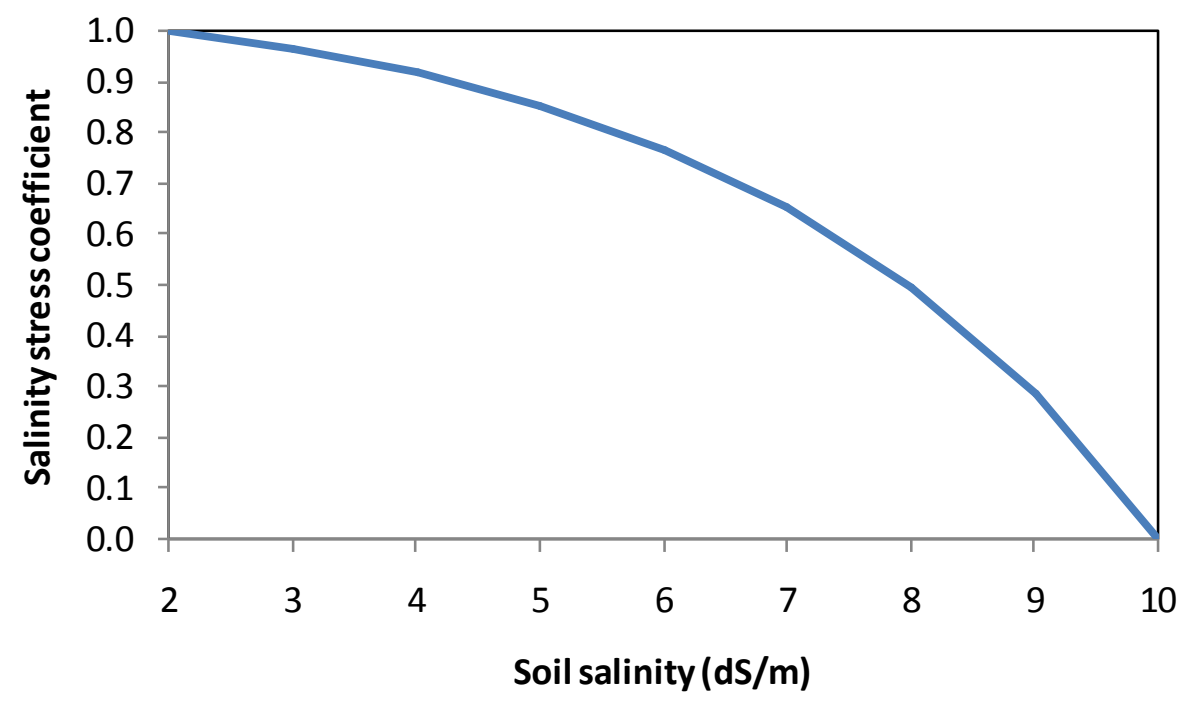

Figure 3: Calibrated soil salinity stress (Ks salt) curve for BRRI Dhan 28

The calibrated parameters were then used to validate the model with the third $\left(T_{3}\right)$ to fifth $\left(T_{5}\right)$ treatments. During validation, irrigation water quality and initial soil salinity were changed according to the measured values under the three treatments. $\mathrm{CC}_{\mathrm{x}}$, time to senescence, length building up $\mathrm{HI}$ and $\mathrm{HI}_{0}$ were provided for optimal conditions as suggested in Raes et al. (2012). Other phenological parameters, such as time to maximum canopy, time to flowering, duration of flowering, maximum rooting depth, time to maximum rooting depth and canopy decline, were provided as observed in the field experiments. There were no significant differences in values of these parameters among the treatments except for time to maximum canopy and maximum rooting depth in the fourth treatment $\left(\mathrm{T}_{4}\right)$.

Table 1: Input values used in the AquaCrop model for calibration under saline water irrigation regime (the second saline water irrigation treatment)

\begin{tabular}{|l|l|}
\hline Parameter with unit & Value used \\
\hline $\mathrm{CC}_{0}(\%)$ & 3 \\
\hline $\mathrm{CC}_{\mathrm{x}}(\%)$ & 95 \\
\hline Canopy decline (days) & 35 \\
\hline Time to recover (DAT) & 7 \\
\hline Time to maximum canopy (DAT) & 64 \\
\hline Time to senescence (DAT) & 72 \\
\hline Time to maturity (DAT) & 98 \\
\hline Time to flowering (DAT) & 68 \\
\hline Duration of flowering (days) & 7 \\
\hline Length building up HI (days) & 30 \\
\hline Determinancy linked with flowering & yes \\
\hline Maximum effective rooting depth (cm) & 38 \\
\hline Time to maximum rooting depth (DAT) & 72 \\
\hline
\end{tabular}




\begin{tabular}{|c|c|}
\hline Minimum effective rooting depth $(\mathrm{m})$ & 0.3 \\
\hline Shape factor describing root zone expansion & 2 \\
\hline Base temperature for GDD $\left({ }^{\circ} \mathrm{C}\right)$ & 8 \\
\hline Upper temperature for GDD $\left({ }^{\circ} \mathrm{C}\right)$ & 30 \\
\hline Crop coefficient for transpiration at CC $=100 \%$ & 1.10 \\
\hline Decline in crop coefficient after reaching $\mathrm{CC}_{\mathrm{x}}(\% /$ day $)$ & 0.15 \\
\hline Effect of canopy cover in reducing soil evaporation in late season (\%) & 50 \\
\hline $\mathrm{WP}^{*}\left(\mathrm{gm} / \mathrm{m}^{2}\right)$ & 19 \\
\hline Reference harvest index (\%) & 50 \\
\hline Leaf growth threshold (pexp, upper) & 0.00 \\
\hline Leaf growth threshold ( $\mathrm{p}_{\text {exp, lower }}$ ) & 0.40 \\
\hline Shape factor for leaf growth stress coefficient curve & 3 \\
\hline Stomatal conductance threshold $\left(\mathrm{p}_{\text {sto }}\right)$ & 0.50 \\
\hline Shape factor for stomata stress coefficient curve & 3 \\
\hline Senescence stress coefficient threshold $\left(\mathrm{p}_{\mathrm{sen}}\right)$ & 0.55 \\
\hline Shape factor for senescence stress coefficient curve & 3 \\
\hline Soil water depletion threshold for failure of pollination $\left(\mathrm{p}_{\mathrm{pol}}\right)$ & 0.75 \\
\hline Possible increase in HI due to water stress before flowering (\%) & 0 \\
\hline Excess of potential fruits (\%) & 200 \\
\hline Coefficient, inhibition of vegetative growth on $\mathrm{HI}$ & 10 \\
\hline Coefficient, inhibition of stomata on HI & 5 \\
\hline Allowable maximum increase of specified HI (\%) & 15 \\
\hline Cold stress temperature for pollination $\left({ }^{\circ} \mathrm{C}\right)$ & 8 \\
\hline Heat stress temperature for pollination $\left({ }^{\circ} \mathrm{C}\right)$ & 35 \\
\hline Salinity stress, lower threshold, $\mathrm{ECe}_{\mathrm{n}}(\mathrm{dS} / \mathrm{m})$ & 2 \\
\hline Salinity stress, upper threshold, $\mathrm{ECe}_{\mathrm{x}}(\mathrm{dS} / \mathrm{m})$ & 10 \\
\hline Shape factor for salinity stress coefficient curve & 2.4 \\
\hline
\end{tabular}

The simulated rice yields and final biomasses for different treatments are plotted along with their corresponding observed values in Figures 4 and 5, respectively. It is seen from both the figures that the model simulates the actual yields and biomasses of the boro rice grown under different saline water regimes quite well. For grain yield, the mean absolute error calculated from the experimental data was only $0.12 \mathrm{t} / \mathrm{ha}$ and the root mean square error was only $0.03 \mathrm{t} / \mathrm{ha}$. For biomass, these values were $0.43 \mathrm{t} / \mathrm{ha}$ and $0.22 \mathrm{t} / \mathrm{ha}$, respectively. 


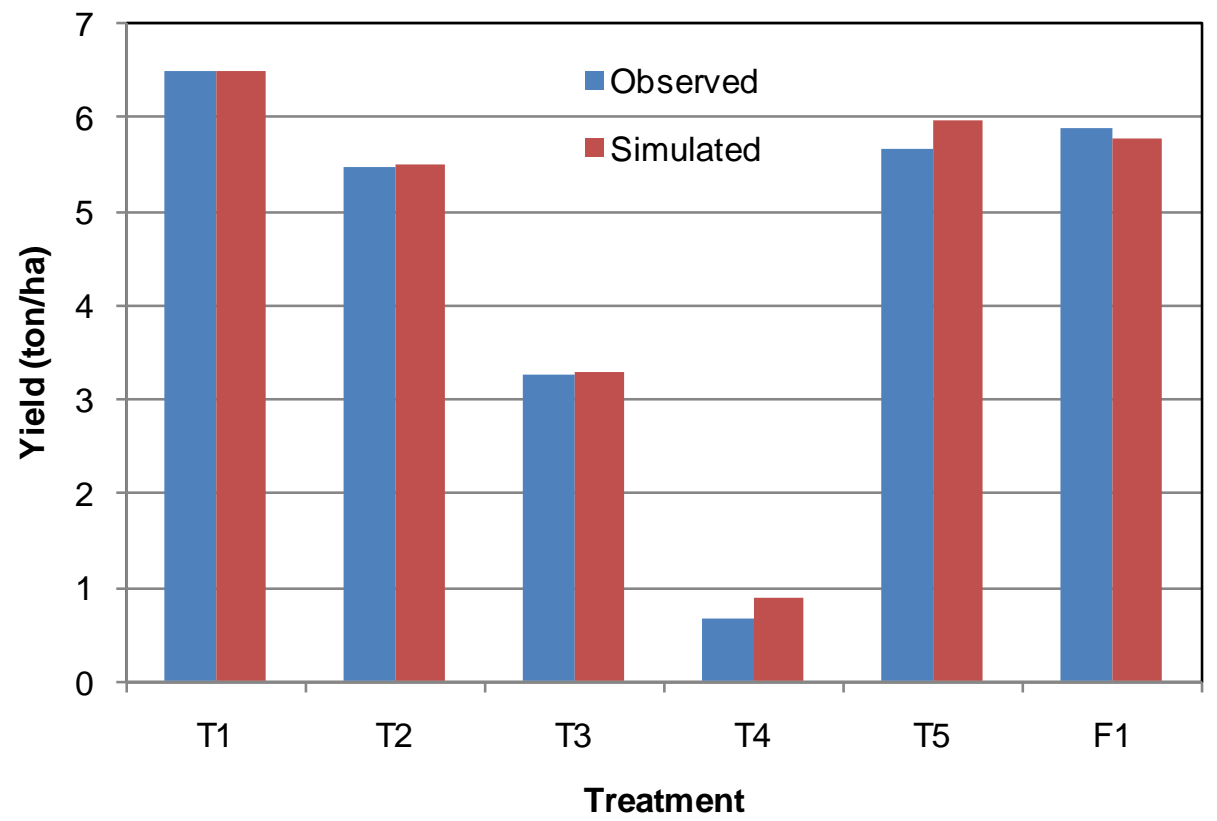

Figure 4: Observed and simulated rice yields under different saline water regimes

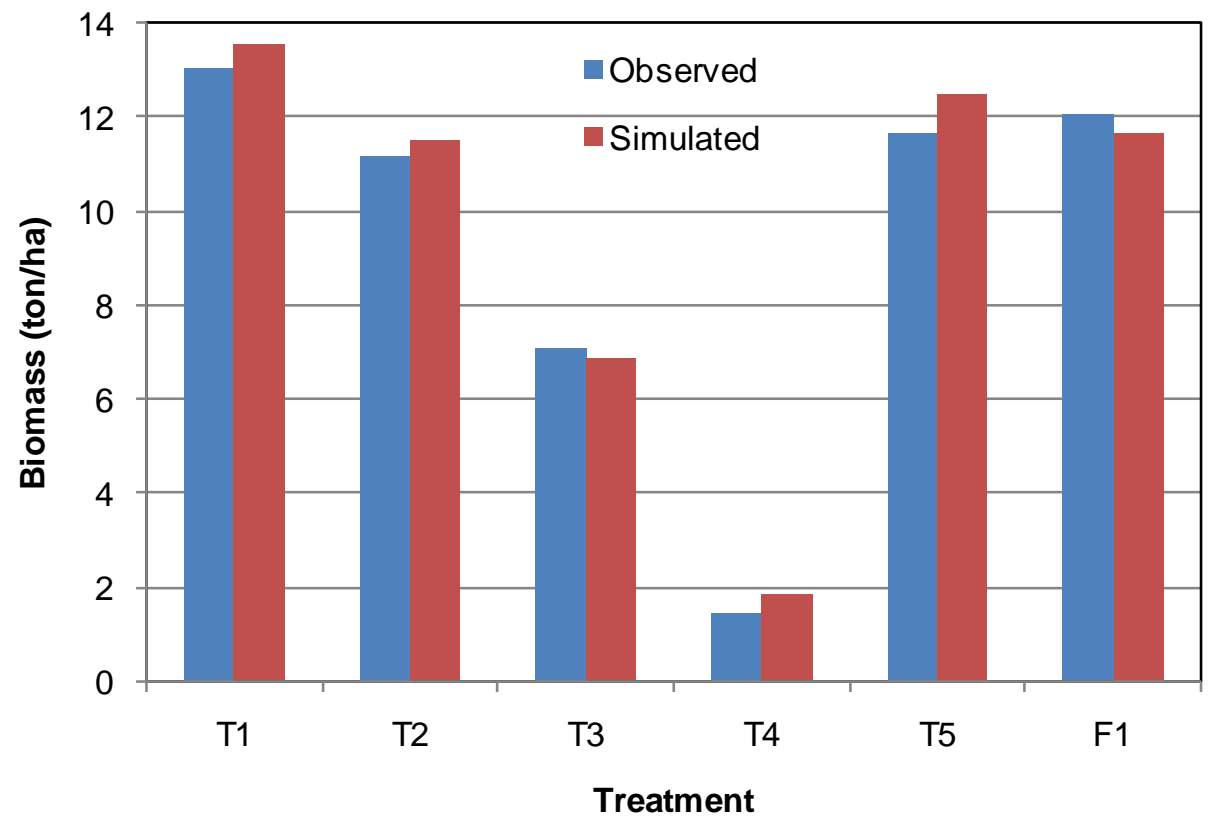

Figure 5: Observed and simulated rice biomasses under different saline water regimes

Since the first treatment $\left(\mathrm{T}_{1}\right)$ was used as the reference treatment indicating no water, salinity and fertility stresses to the crop, the yield obtained was the potential yield for this particular variety in the given climatic and field conditions. The observed rice yield under the first treatment was $6.49 \mathrm{t} / \mathrm{ha}$, which was very close to the simulated yield of $6.52 \mathrm{t} / \mathrm{ha}$. The observed biomass at harvest was $13.03 \mathrm{t} / \mathrm{ha}$ and the simulated biomass was $13.55 \mathrm{t} / \mathrm{ha}$. 
Since the irrigation water salinity in the treatment $\mathrm{T}_{1}$ was around $3 \mathrm{dS} / \mathrm{m}$, which is slightly higher than the lower threshold of $2 \mathrm{dS} / \mathrm{m}$ used in the model calibration and validation discussed earlier in this section, the model was rerun for this treatment considering the salinity stress. The simulated yield during this time was found to be $6.48 \mathrm{t} / \mathrm{ha}$ and the biomass to be $13.49 \mathrm{t} / \mathrm{ha}$. The model results also indicated a soil salinity stress of only $3 \%$ in an average crop cycle in this treatment. The effect of salinity, which is due to the consideration of salinity stress, was a reduction in yield of $0.49 \%$ and in biomass of $0.49 \%$. The model results also indicated that during the period from 24 January to 1 May 2013, total $\mathrm{ET}_{0}$, rainfall, irrigation and growing degrees were $316 \mathrm{~mm}, 53 \mathrm{~mm}, 1080 \mathrm{~mm}$ and $1341^{\circ} \mathrm{C}$, respectively. Simulated evaporation and crop transpiration were $91 \mathrm{~mm}$ and $236 \mathrm{~mm}$, respectively, and the drainage volume from the root zone was $876 \mathrm{~mm}$. The water productivity was found to be $1.98 \mathrm{~kg}$ of rice grain per cubic meters of water evapotranspired.

The applicability of the model was further tested in a different agro-ecological setting at Satkhira in the southwest coastal Bangladesh. The same variety of rice (BRRI Dhan 28) was cultivated by a farmer in his own field (referred to as farmer's field ' $F 1$ ' in Figures 4 and 5) following the local practice and input uses. The planting date of 44 days old seedling was 8 February and the harvesting date was 8 May 2013. The field was monitored throughout the growing period, and the required data for the AquaCrop model were gathered. The model was then run keeping its parameters the same as the calibration and validation runs with the experimental data in Gazipur in central Bangladesh. The yield obtained by the farmer was $5.90 \mathrm{t} / \mathrm{ha}$ and that simulated by the model was $5.79 \mathrm{t} / \mathrm{ha}$. These results further indicate that the calibrated AquaCrop model captures the yield variation of the boro rice reasonably well. The calibrated model can be used to assess the vulnerability of the rice crop to changes in soil and water salinity and climatic parameters due to global warming induced climate change. Work is currently underway in that direction.

\section{Conclusions}

The AquaCrop model was parameterized and tested for boro rice under different saline soil and irrigation conditions in Bangladesh. A field experiment was conducted in central Bangladesh and a field monitoring was carried out in southwest coastal region of the country in the year of 2013 to gather required input data and information for the model. The results indicated that the model captured the grain yield variation of BRRI Dhan 28 with salinity variation reasonably well. The crop response versus soil salinity stress curve was found to be convex in shape with a lower threshold of $2 \mathrm{dS} / \mathrm{m}$, an upper threshold of $10 \mathrm{dS} / \mathrm{m}$ and a shape factor of 2.4. The model can be used to predict the impacts of future changes in water and soil salinity as well as climatic parameters on rice yield in Bangladesh.

\section{Acknowledgement}

This manuscript is prepared based on a research project titled "Assessing health, livelihoods, ecosystem services and poverty alleviation in populous deltas"' sponsored by DFID, NERC and ESRC. 


\section{References}

1 M. Q. Mirza, Diversion of the Ganges water at Farakka and its effects on salinity in Bangladesh, Environ. Manage., 1998, 22(5), 711-722.

2 M. S. Mondal, M. R. Jalal, M. S. A. Khan, U. Kumar, R. Rahman and H. Huq, Hydrometeorological trends in southwest coastal Bangladesh: perspectives of climatechange and human interventions, Am. J. Clim. Change,2013, 2(1), 62-70.

3 Q. Schiermeier, Holding back the tide, Nature, 2014, 508,164-166.

4 M. S. Hossain, J. A. Dearing, M. M. Rahman and M. Salehin, Recent changes in ecosystem services and human well-being in the Bangladesh coastal zone, Reg. Environ. Change, 2015, DOI: $10.1007 / \mathrm{s} 10113-014-0748-z A$.

5 P. Steduto, T. C. Hsiao, D. Raes and E. Fereres, AquaCrop - the FAO cropmodel to simulate yield response to water: I. concepts and underlying principles, Agron. J., 2009, 101(3), 426-437. 6 D. Raes, P. Steduto, T. C. Hsiao and E. Fereres, AquaCrop - the FAO crop model to simulate yield response to water: II. main algorithms and so $\square$ ware description, Agron. J., 2009, 101(3), 438-447.

7 T. C. Hsiao, L. Heng, P. Steduto, B. Rojas-Lara, D. Raes and E. Fereres, AquaCrop - the FAO crop model to simulate yield response to water: III. parameterization and testing for maize, Agron. J., 2009, 101(3), 448-459.

8 L. K. Heng, T. Hsiao, S. Evett, T. Howell and P. Steduto, Validating the FAO AquaCrop model for irrigated and water de $\square$ cient maize, Agron. J., 2009, 101(3), 488-498.

9 M. Abedinpour, A. Sarangi, T. B. S. Rajput, M. Singh, H. Pathak and T. Ahmad, Performance evaluation of AquaCrop model for maize crop in a semi-arid environment, Agr. Water Manag., 2012, 110, 55-66.

10 R. Stricevic, M. Cosic, N. Djurovic, B. Pejic and L. Maksimovic, Assessment of the FAO AquaCrop model in the simulation of rainfed and supplementally irrigated maize, sugar beet and sun $\square$ ower, Agr. Water Manag., 2011, 98, 1615-1621.

11 B. Andarzian, M. Bannayan, P. Steduto, H. Mazraeh, M. E. Barati and A. Rahnama, Validation and testing of the AquaCrop model under full and de $\square$ cit irrigated wheat production in Iran, Agr. Water Manag., 2011, 100, 1-8.

12 H. Salemi, M. A. M. Soom, T. S. Lee, S. F. Mousavi, A. Ganji and K. Yousoff, Application of AquaCrop model in de $\square$ cit irrigation management of winter wheat in arid region, Afr. J. Agric. Res., 2011, 610, 2204-2215.

13 M. S. Mkhabela and P. R. Bullock, Performance of the FAO AquaCrop model for wheat grain yield and soil moisture simulation in Western Canada, Agr. Water Manag., 2012, 110, 16-24.

14 A. Araya, S. Habtu, K. M. Hadgu, A. Kebede and T. Dejene, Test of AquaCrop model in simulating biomass and yield of water de $\square$ cient and irrigated barley, Agr. Water Manag., 2010, 97, 1838-1846.

15 F. Hussein, M. Janat and A. Yakoub, Simulating cotton yield response to de $\square$ cit irrigation with the FAO AquaCrop model, Spanish J. Agr. Res., 2011, 9(4), 1319-1330.

16 A. Araya, S. D. Keesstra and L. Stroosnijder, Simulating yield response to water of Teff with FAO's AquaCrop model, Field

Crop. Res., 2010, 116, 196-204.

17 S. Geerts, D. Raes, M. Garcia, R. Miranda, J. A. Cusicanqui, C. Taboada, J. Mendoza, R. Huanca, A. Mamani, O. Condori, J. Mamani, B. Morales, V. Osco and P. Steduto, Simulating yield response of quinoa to water availability with AquaCrop, Agron. J., 2009, 101(3), 499-508. 
18 L. Lin, B. Zhang and L. Xiong, Evaluating yield response of paddy rice to irrigation and soil management with application of the AquaCrop model, Trans. ASABE, 2012, 55(3), 839-848. 19 T. Bhattacharya and R. K. Panda, Effect of climate change on rice yield at Kharagpur, West Bengal, Int. J. Food, Agric. Vet. Sci., 2013, 4(2), 6-12.

20 Z. Katambara, F. C. Kahimba, W. B. Mbungu, P. Reuben, M. Maugo, F. D. Mhenga and H. F. Mahoo, Optimizing system of rice intensi $\square$ cation parameters using Aquacrop model for increasing water productivity and water use efficiency on rice production in Tanzania, J. Agric. Sustainability, 2013, 4(2), 235-244.

21 B. Nikolaus, Rice production in Africa: simulation of rice production and water productivity using AquaCrop in an inland valley in Central Benin, Master's thesis, Department of Hydrology and Water Resources Management, Kiel University, Germany, 2013.

22 M. Mainuddin, M. Kirby and C. T. Hoanh, Impact of climate change on rainfed rice and options for adaptation in the lower Mekong Basin, Nat. Hazards, 2012, 66(2), 905-938. 23 BBS, 2011 Yearbook of Agricultural Statistics of Bangladesh Bangladesh Bureau of Statistics, Dhaka, 2011.

24 BBS, Report of the Household Income and Expenditure Survey 2010, Bangladesh Bureau of Statistics, Dhaka, 2011.

25 WARPO, Dra $\square$ Development Strategy, Annex C: Land and Water Resources, Water Resources Planning Organization, Dhaka, 2000.

26 BBS, Population and Housing Census 2011, Bangladesh Bureau of Statistics, Dhaka, 2011. 27 GED, 6th Five Year Plan FY 2011-FY 2015: Accelerating Growth and Reducing Poverty, General Economics Division, Planning Commission, Dhaka, 2011.

28 MoA, National Agriculture Policy, Ministry of Agriculture, Dhaka, 2013.

29 SRDI, Saline Soils of Bangladesh, Soil Resource Development Institute, Ministry of Agriculture, Dhaka, 2012.

30 J. Doorenbos and A. H. Kassam, Yield response to water, FAO Irrigation and Drainage Paper 33, Rome, 1979.

31 P. Steduto, D. Raes, T. C. Hsiao, E. Fereres, L. K. Heng, T. A. Howell, S. R. Event, B. A. Rojas-Lara, H. J. Farahani, G. Izzi, T. Y. Oweis, S. P. Wani, J. Hoogeveen and S. Geerts, Concepts and applications of AquaCrop: the FAO crop water productivity model, in Crop Modeling and Decision Support, ed. W. Cao, J. W. White and E. Wang, 2009, pp.

175-191.

32 D. Raes, S. Geerts, E. Kipkorir, J. Wellens and A. Sahli Simulation of yield decline as a result of water stress with a robust soil water balance model, Agr. Water Manag., 2006, 81, 335-357.

33 D. Raes, P. Steduto, T. C. Hsiao and E. Fereres, Reference Manual, AquaCrop Version 4.0, FAO, Land and Water Division, Rome, 2012.

34 BRRI, Modern Rice Cultivation, Bangladesh Rice Research Institute, Gazipur, 11th edn, 2004.

35 SRDI, Analytical Methods: Soil, Water, Plant Material and Fertilizer, Soil Resource Development Institute, Ministry of Agriculture, Dhaka, 2nd edn, 2012.

36 Z. Saadati, N. Pirmoradian and M. Rezaei, Calibration and evaluation of AquaCrop model in rice growth simulation under different irrigation managements, ICID $21^{\text {st }}$ International Congress on Irrigation and Drainage, Tehran, Iran, 2011, pp. 589-600.

37 BARC, Fertilizer Recommendation Guide - 2012, Bangladesh Agricultural Research Council, Dhaka, 2012. 
38 R. G. Allen, L. S. Pereira, D. Raes and M. Smith, Crop Evapotranspiration - Guidelines for Computing Crop Water RequirementsFAO Irrigation and Drainage Paper 56, Rome, 1998. 